\title{
THE INFLUENCE OF DIFFERENT ETCHING MODES AND ETCHING TIME PERIODS ON MICRO-SHEAR BOND STRENGTH OF MULTI-MODE UNIVERSAL ADHESIVES ON DENTIN
}

\author{
Gülbike Demirel ID, İsmail H. Baltacıoğlu ID \\ Restorative Dentistry, Ankara University Faculty of Dentistry, Turkey
}

\begin{abstract}
INTRODUCTION: Simplifying single-bottle adhesive technology to satisfy clinicians' demand for adhesive procedures, particularly in terms of making the techniques faster, less technically sensitive, and more user friendly, has led to the development of multi-mode universal adhesives, which were designed to bind to tooth structures via the etch-and-rinse, the self-etch, and the selective-etch modes using a single bottle of adhesive solution.

ОвJECTIVEs: The aim of this study was to determine the dentin bonding ability of multi-mode universal adhesive systems in relation to different etching modes and etching time periods using micro-shear bond strength analysis. MATERIAL AND METHODs: Three multi-mode universal adhesives and one etch-and-rinse adhesive were assessed in this study. Micro-shear bond strengths ( $\mu$ SBS) to dentin were obtained in etch-and-rinse (etching $5 \mathrm{~s} / 10 \mathrm{~s} / 15 \mathrm{~s}$ ) and self-etch modes. For each test condition, 10 specimens were prepared for each group. A scanning electron microscope (SEM) was used to examine representative bonded specimens, treated dentin surfaces, and the resin/dentin interface for each test condition.

RESULTS: Multi-mode universal adhesives showed the lowest $\mu$ SBS results in etch-and-rinse mode for 10-s and 15 -s etching $(p<0.05)$. Universal adhesives and self-etch adhesives showed similar $\mu$ SBS values in self-etch mode $(p>0.05)$.

ConcLusions: Analysis concluded that phosphoric-acid etching for time periods greater than $5 \mathrm{~s}$ significantly reduced the efficacy of bonds when using multi-mode universal adhesives.
\end{abstract}

KEY WORDs: universal adhesive, self-etch adhesive, etch-and-rinse adhesive, micro-shear bond strength.

J Stoma 2019; 72, 3: 118-128

DOI: https://doi.org/10.5114/jos.2019.87527

\section{INTRODUCTION}

The prognosis of adhesive restorations depends mainly on adhesive bond strength and the durability of the adhesive interface [5]. Innovations in adhesive technology lead to the development of a new generation of adhesive systems. Currently, dental adhesive systems are divided into two main groups named as "etch-rinse" or "self-etch" strategies. In addition, these systems can be classified according to the application stages: two- or three-step systems for those using acid etching, and for self-etching it can be classified in one- or two-step systems $[18,36]$.

In etch-and-rinse adhesion strategy, the first step includes demineralisation with phosphoric acid; this

JOURNAL OF STOMATOLOGY

AdDress for CORRESPONDENCE: Dr. Gülbike Demirel, Restorative Dentistry, Ankara University Faculty of Dentistry, Turkey, e-mail: gulbikedemirel@gmail.com,gdemirel@ankara.edu.tr 
increases the adhesive penetration. After the demineralisation, the upper inter-tubular matrix changes and nanoscale porosities form with the underlying collagen fibrils. The following step is the conditioning of the dentin surface with a primer, and the final step is the application of adhesive resin. These two materials can be applied either separately or in a single solution [18]. In addition to the fact that this technique involves several steps, one of the disadvantages of etch-and-rinse adhesive systems is that the collagen fibres collapse as the demineralised dentin dries; this can lead to a reduction in bond strength [29]. Therefore, it is important to keep the etched dentin moist for effective resin infiltration into the demineralised areas $[11,19]$. In particular, the definition of an "ideal moisture" content depends on various factors: (1) clinician experience [25]; (2) the "directions for use" recipe of the material [12]; and (3) the solvent type present in the composition [22]. However, standard guidelines have not been established with respect to how moisture should be retained, and this remains a significant challenge for clinicians and researchers.

Unlike etch-and-rinse adhesives, self-etch adhesives do not involve a divided etching step because they involve an aqueous mixture of acidic functional monomers, usually phosphoric-acid esters [36], and the degree of moisture affects them less than etch-and-rise adhesives [30]. Therefore, previous authors have claimed that this approach is more user friendly and less technically sensitive, and results in a more reliable clinical performance [20, 32]. Nevertheless, phosphoric acid is still often recommended for etching of the enamel, particularly in the selective-etch technique when cavity margins end in the enamel [16]. However, when low-viscosity acid is used, accidental etching may occur on the dentin surface during the enamel-etching process, and this etching procedure is generally considered to be unsuitable for use on the dentin substrate for self-etch adhesives [33].

Manufacturers often want to produce user-friendly products with fewer components, which require less technical precision and produce faster results. These systems are single bottles and can be used as either totaletch, selective-etch, or self-etch [8]. These new materials are highly versatile and provide clinicians with various bonding strategies.

When using the total-etch method, it is necessary to apply acid to dental tissues for a certain period of time. Many studies have been published on different etching periods and their relative effect on dentin when using etch-and-rinse adhesive systems [39]. However, there is a lack of information on the appropriate etching period for dentin when using multi-mode universal adhesives in etch-and-rinse mode.

\section{OBJECTIVES}

The aim of the current research was to compare the bond strength with various etching modes and time periods using three multi-mode universal adhesives with two self-etch adhesives and an etch-and-rinse adhesive on dentin.

\section{MATERIAL AND METHODS}

This study was planned and conducted under the approval of faculty Ethics Committee (Ankara University, Faculty of Dentistry 36290600/14).

\section{TOOTH SELECTION AND PREPARATION}

In total, 170 extracted sound human third molars were used for this experiment $(N=170)$. After removing residual tissue tags, extracted teeth were stored in $0.9 \%$ saline solution, and specimens were prepared for experimentation within two weeks. The occlusal surfaces of extracted teeth were removed with a cutting machine under water-cooling (Micracut 201, Metkon, Turkey) to obtain flat dentin surfaces and then embedded in a selfcured acrylic resin (Vertex Self Curing, Vertex Dental, Netherlands). The occlusal parts of the teeth were polished with silicon carbide paper (600-grit) under water-cooling (P1000-P4000Metkon, Gripo 2v GrinderPolisher, Turkey) to create a uniform smear layer.

All surfaces were then carefully verified using a stereomicroscope at 25× magnification (M3Z, Leica Microsystems, Wetzlar, Germany) to ensure the absence of pulpal exposure and residual enamel.

\section{BONDING PROCEDURES}

Three multi-mode universal adhesives (Single Bond Universal [SBU] [3M ESPE, USA], All Bond Universal [ABU] [Bisco Inc., USA], and Clearfil Universal Bond [CUB] [Kuraray Noritake Dental Inc., Japan]), one two-step self-etch adhesive (Clearfil SE Bond [CSE] [Kuraray Noritake Dental Inc., Japan]), one one-step selfetch adhesive (Clearfil S3 Bond Plus [CS3] [Kuraray Noritake Dental Inc., Japan]), and one etch-and-rinse adhesive (Adper Single Bond-2 [ASB2] [3M ESPE, USA]) were selected for this study. The compositions of these adhesives are listed in Table 1.

The teeth were divided into six groups and randomly assigned to one of the six adhesives. Adhesives were then applied to occlusal dentin surfaces using different etching modes and periods $(n=10)$ as follows:

- self-etching mode,

- etch-and-rinse mode (5-s etching),

- etch-and-rinse mode (10-s etching),

- etch-and-rinse mode (15-s etching). 


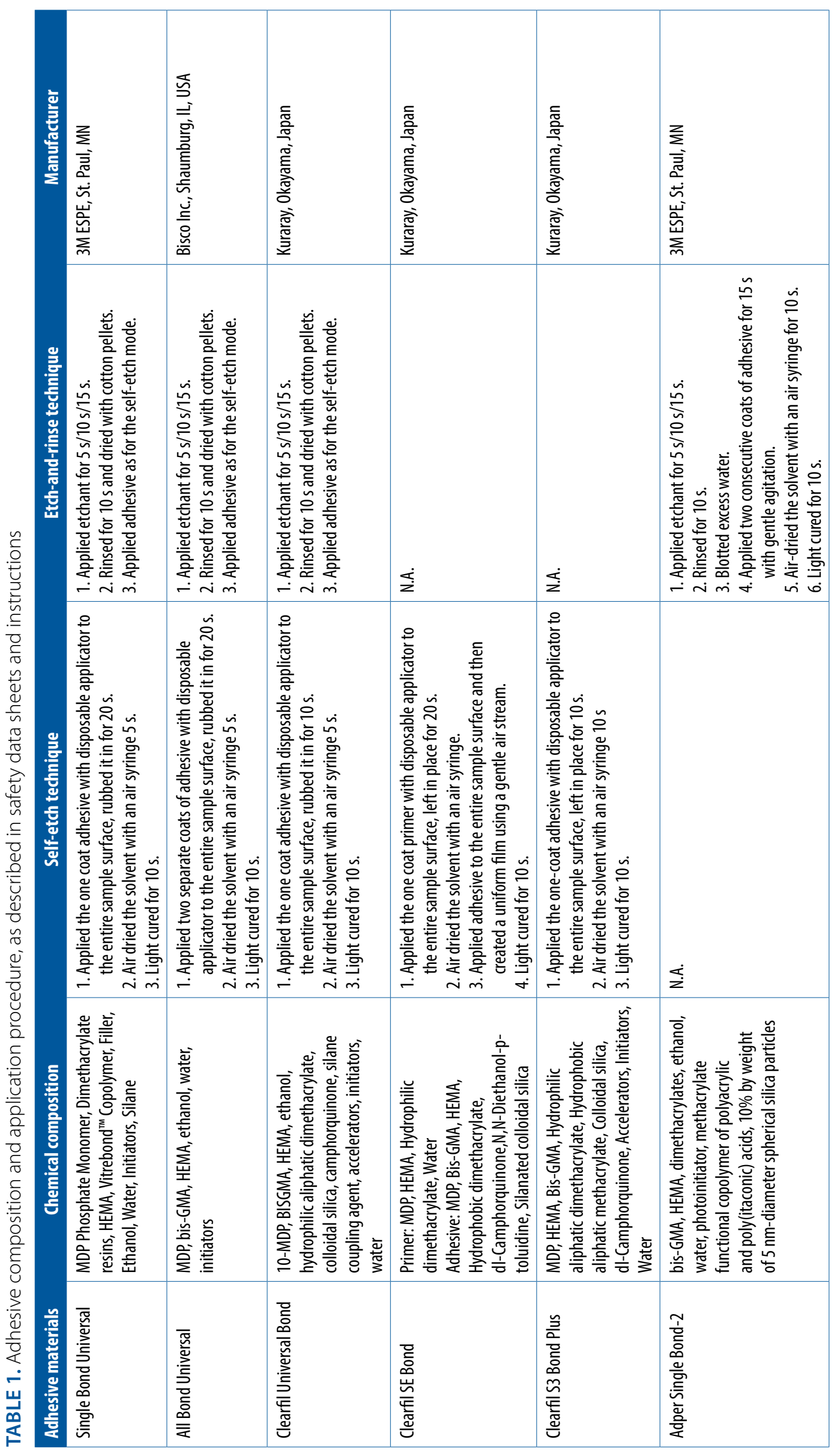




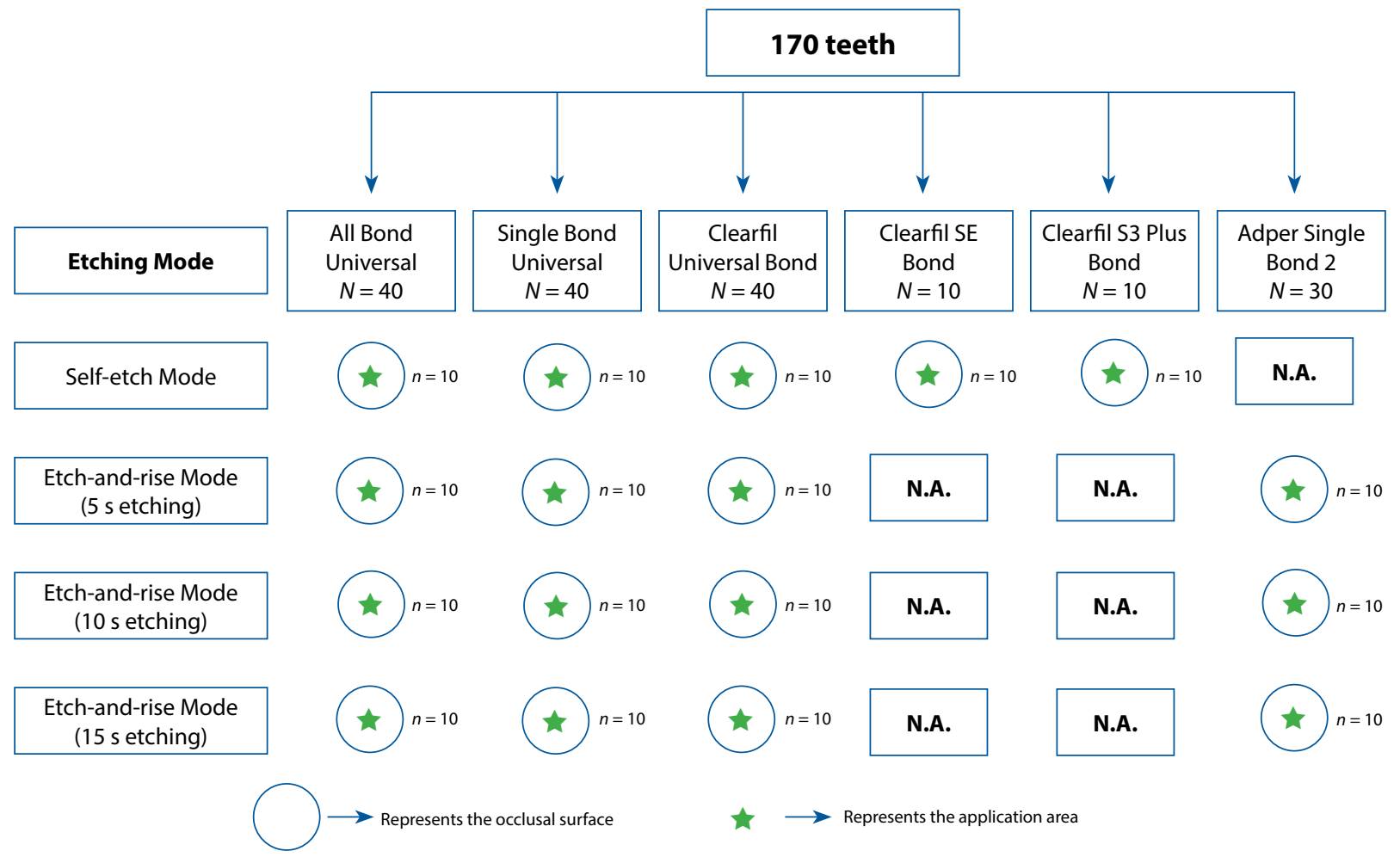

FIGURE 1. Study design

For the etch-and-rinse mode, a 35\% phosphoricacid etchant (K-ETCHANT Syringe, Kuraray Noritake Dental Inc., Okayama, Japan) was used for etching occlusal dentin surface for $5 \mathrm{~s} / 10 \mathrm{~s} / 15 \mathrm{~s}$. Then, etched dentin surfaces were rinsed for $10 \mathrm{~s}$. The water present on the rinsed dentin surface was removed according to the manufacturer's instructions for each respective adhesive. For the self-etch mode, no etchant was used, and the tested adhesives were applied to the dentin surface according to the manufacturer's instructions. The experimental design is illustrated in Figure 1.

Afterwards, a polyethylene tube $(0.5 \mathrm{~mm}$ in height and of $0.8 \mathrm{~mm}$ internal diameter [Unomedical, ConvaTec Limited, UK]) was placed on the bonding area and cured by light for $10 \mathrm{~s}$ with a LED-curing unit (SDI Radii Plus, SDI Limited, Australia). Efforts were made to ensure that light intensity was $\geq 1000 \mathrm{~mW} / \mathrm{cm}^{2}$ using a Hilux Ledmax curing lightmeter (Benlioglu Dental, Turkey). Then, resin composite (Clearfil Majesty Esthetic, Kuraray Noritake Dental Inc., Okayama, Japan) was condensed into the tube with a composite filling instrument (Polyfill, 1051/95, Carl Martin GmbH, Solingen, Germany). The tube was then light cured for $20 \mathrm{~s}$, and following this procedure the polyethylene tube was removed and each specimen was examined under a stereomicroscope (M3Z, Leica Microsystems, Wetzlar, Germany) at $25 \times$ magnifications to verify that no interfacial gaps, bonding defects, or air bubble inclusions were present. Then, all specimens were subjected to a thermo-cycle process $\left(5-55^{\circ} \mathrm{C}, 10,000\right.$ cycles $)$.

\section{MICRO-SHEAR BOND STRENGTH AND FAILURE ANALYSIS}

Each bonded interface was subjected to a $\mu \mathrm{SB}$ test in a universal testing machine (Z010, Zwick, Ulm, Germany) using a chisel-shaped blade to deliver a force parallel to the bonded surface, loaded at a crosshead speed of $1 \mathrm{~mm} / \mathrm{min}$ until failure. The load at debonding was recorded, and $\mu$ SBS $\sigma$ was calculated using the load at failure $\mathrm{F}(\mathrm{N})$ in the adhesive area $\mathrm{A}\left(\mathrm{mm}^{2}\right): \sigma=\mathrm{F} / \mathrm{A}$.

Further, the deboned areas were examined under stereomicroscope at $25 \times$ magnification (M3Z, Leica Microsystems, Wetzlar, Germany). Failures were classified as: (1) cohesive failure exclusively in dentin, (2) cohesive failure exclusively in the resin composite, (3) adhesive failure at the interface and mix failure at the adhesive/dentin interface, which included cohesive failure of the dentin and/or resin composite, and (4) adhesive material.

\section{SCANNING ELECTRON MICROSCOPY ANALYSIS}

Three samples were prepared for each group in the same manner as for the bonding procedures, but tubes with $5 \mathrm{~mm}$ diameter were used. The embedded specimens were cut into two halves longitudinally in a mesial/distal direction using a low-speed cutting machine. After $24 \mathrm{~h}$, the surfaces of the cut halves were polished with 600-, $800-$, and 1200-grit abrasive paper. The specimens were then etched with $35 \%$ phosphoric acid for $5 \mathrm{~s}$, immersed 
in $5 \%$ sodium hypochlorite for $5 \mathrm{~min}$, rinsed with distilled water, and then dried in a desiccator cabinet for two days. Surfaces were then sputter-coated with 5-nm gold/ palladium particles (EMS150R S Sputter Coater, Electron

TABLE 2. Micro-shear bond strength ( $\mu S B S$ ) values (MPa) for the different adhesive systems tested. Mean values with the same letters are not significantly different $(p>0.05)$

\begin{tabular}{|c|c|c|c|}
\hline Adhesive system & Etching mode & $\mu S B S$ mean & SD \\
\hline \multirow[t]{4}{*}{ Single Bond Universal } & 5 -s etching & $25.35(\mathrm{a})$ & 5.9 \\
\hline & 10-s etching & $22.55(b)$ & 3.9 \\
\hline & 15-s etching & $20.05(b)$ & 3.7 \\
\hline & Self-etch & $30.25(\mathrm{a})$ & 5.7 \\
\hline \multirow[t]{4}{*}{ All Bond Universal } & 5-s etching & 31.4(a) & 4.5 \\
\hline & 10-s etching & 18.7(b) & 5.1 \\
\hline & 15-s etching & $16.85(\mathrm{~b})$ & 2.6 \\
\hline & Self-etch & $30.75(\mathrm{a})$ & 3.8 \\
\hline \multirow[t]{4}{*}{ Clearfil Universal Bond } & 5-s etching & $28.25(\mathrm{a})$ & 5.6 \\
\hline & 10-s etching & $20.9(b)$ & 5.2 \\
\hline & 15-s etching & 14.7(b) & 3.3 \\
\hline & Self-etch & 31.2(a) & 4.0 \\
\hline Clearfil SE Bond & Self-etch & 29.4(a) & 3.3 \\
\hline Clearfil S3 Bond Plus & Self-etch & 27.3(a) & 4.4 \\
\hline \multirow[t]{3}{*}{ Adper Single Bond-2 } & 5-s etching & $17.75(b)$ & 4.5 \\
\hline & 10-s etching & 28.8(a) & 4.8 \\
\hline & 15-s etching & 33.45(a) & 2.9 \\
\hline
\end{tabular}

Microscopy Sciences, Hotfield, USA). The ultra-structures of all dentin-adhesive interface specimens were then observed with SEM (FEI Inspect F50 FEQ, Thermo Fisher Scientific Inc., Oregon, USA).

\section{STATISTICAL ANALYSIS}

The statistical program GraphPad Prism (ver. 6.0) was used to analyse the data. The Kolmogorov-Smirnov test was used to confirm normal data distribution $(\alpha=0.05)$. Obtained data were then analysed by oneway analysis of variance, and the Tukey HSD post hoc test was used for multiple comparisons. The level of significance was set at $p<0.05$.

\section{RESULTS}

The effects of acid etching modes and times on $\mu$ SBS are shown in Table 2. Multi-mode adhesives (SBU, ABU, CUB) showed higher bond strength values in self-etch and 5-s etch-and-rinse modes than in 10-s and 15-s etch-and-rinse modes $(p<0.05)$. In self-etch mode, all of the tested adhesives (SBU, ABU, CUB, CSE, CS3) showed similar $\mu$ SBS results $(p>0.05)$. The etch-andrinse adhesive (ASB2) showed significantly higher $\mu$ SBS values when used with 10 -s and 15 -s etching modes than with 5 -s etching mode $(p<0.05)$.

The most common failure in all groups was the adhesive type (Figure 2). For all adhesives tested in etchand-rise mode, SEM images demonstrated funnel- or cylindrical-shaped resin tags, along with lateral ramifi-

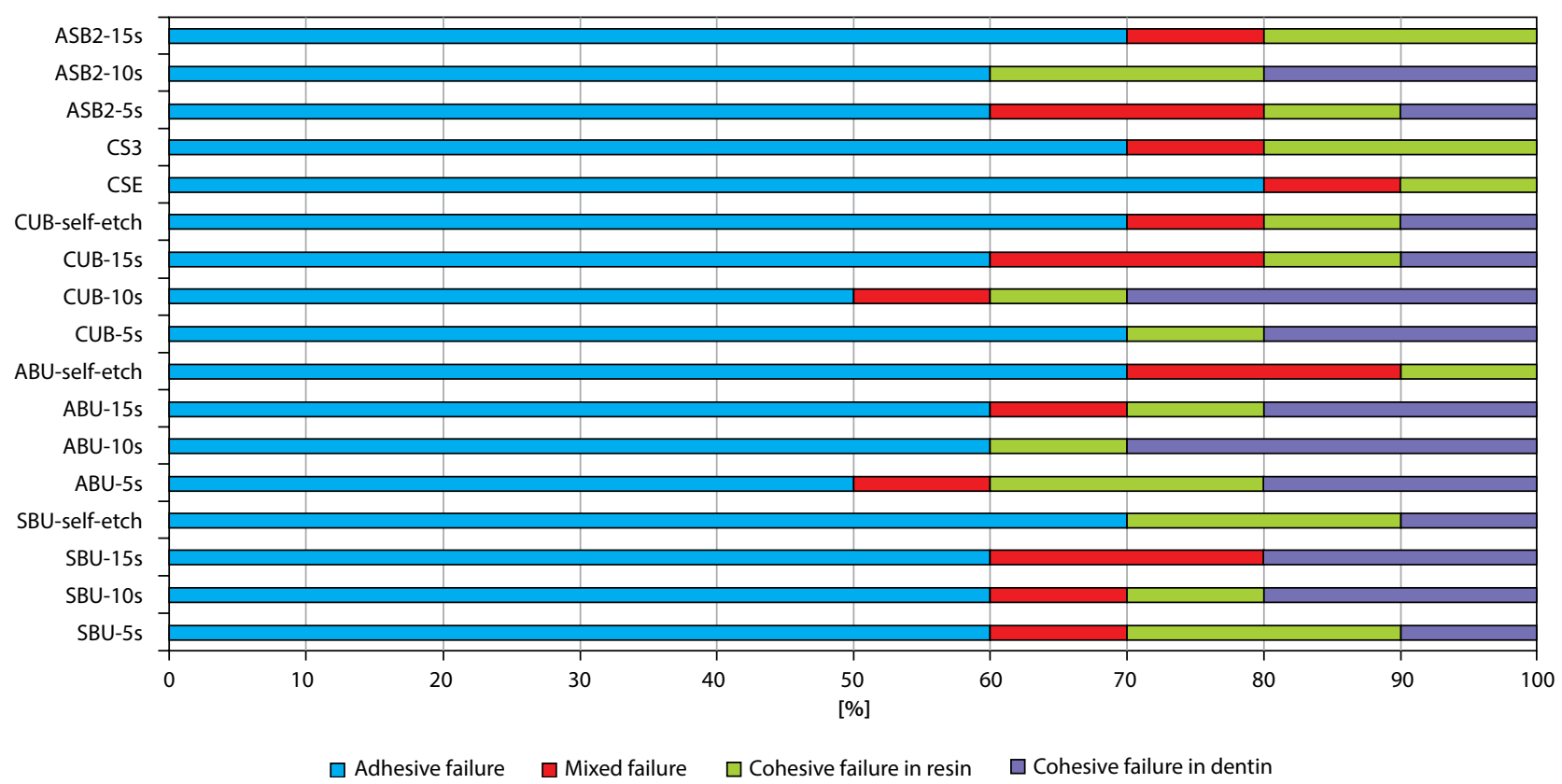

FIGURE 2. Failure mode distribution. Adhesive failures were the most common form of failure in each group (SBU Single Bond Universal, ABU - All Bond Universal, CUB - Clearfil Universal Bond, CSE - Clearfil SE Bond, CS3 - Clearfil S3 Bond Plus, ASB2 - Adper Single Bond-2) 

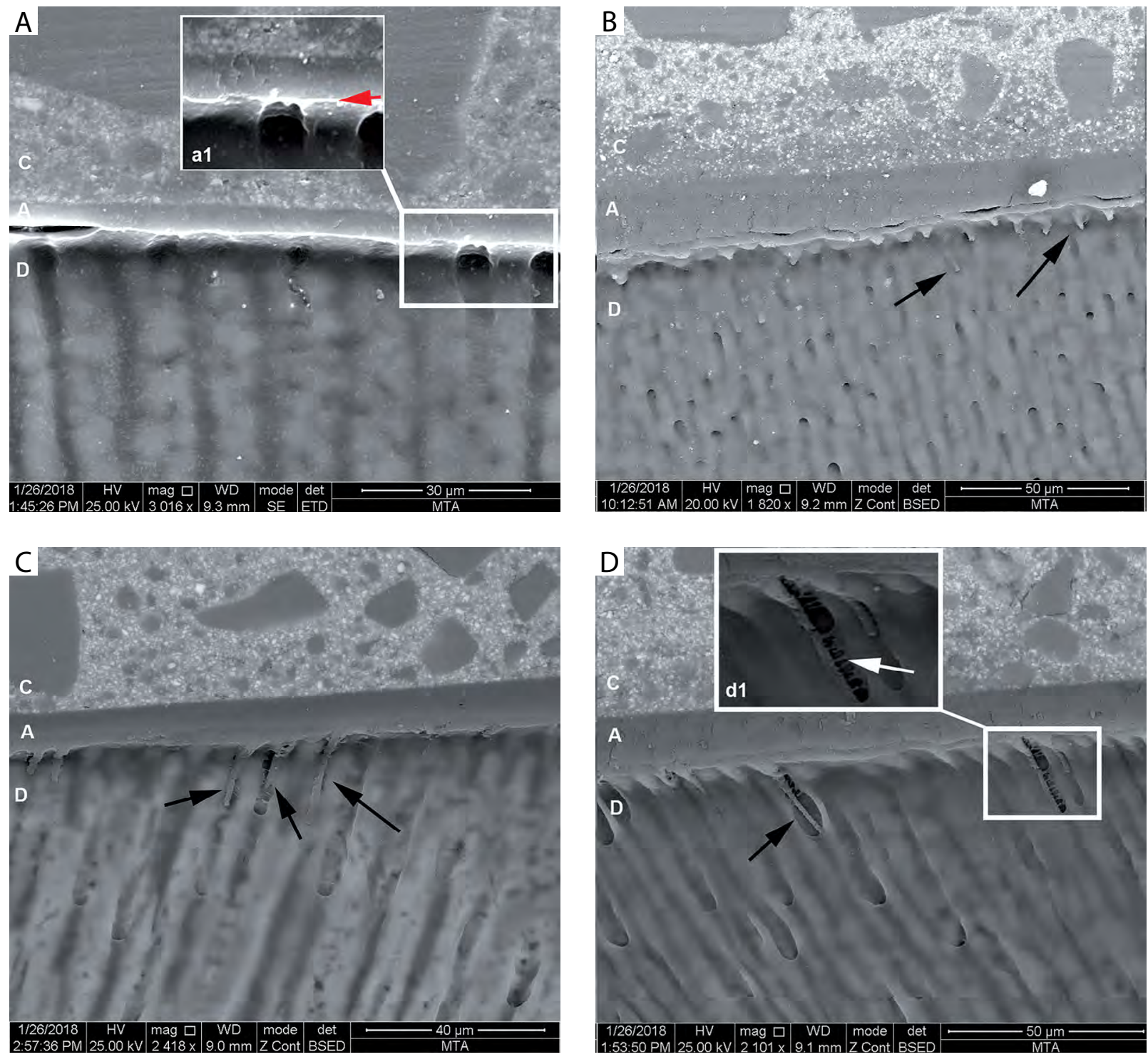

FIGURE 3. Representative scanning electron microscopy (SEM) images of the resin-dentin interface bonded with Single Bond Universal adhesive in different etching modes. A) In self-etch mode, continuous hybrid layer (a1 - red arrow) with no resin tags. B-D) In etch-and-rinse mode with 5-s, 10-s, and 15-s etching. Funnel-shaped resin tags (black arrow) with lateral ramifications (white arrow). C - composite, A - adhesive, D - dentin

cations. In contrast, resin tags were not observed in any of the adhesives applied in self-etch mode, except twostep CSE bonding (Figures 3-7).

\section{DISCUSSION}

The launch of the universal adhesives was a notable development in adhesive dentistry. These adhesive systems can be used for different substrates with different application techniques and were composed as an "allin-one" approach from the "one-step self-etch" systems. Versatile usability allows clinicians to modify the technique according to different clinical situations.

The findings of the current research showed that all of the tested multi-mode universal adhesives exhibited a homogeneous behaviour with different etching modes and time periods. Higher $\mu$ SBS values were detected while multi-mode universal adhesives were applied in the self-etch mode and exhibited similar $\mu$ SBS results with one-step system, two-step self-etch system, and etch-and-rinse system (in 10-s and 15-s etching).

It may be reasonable to assume that the universal and self-etch adhesives showed similar $\mu$ SBS values in the current investigation because of the similarities in their chemical formulas. All the adhesives tested, except for Adper Single Bond2, contained a functional 10-methacryloyloxydecyl dihydrogen phosphate monomer (MDP). MDP can chemically bond to the tooth structure; for this reason, a large number of manufacturers produce MDP containing adhesive 

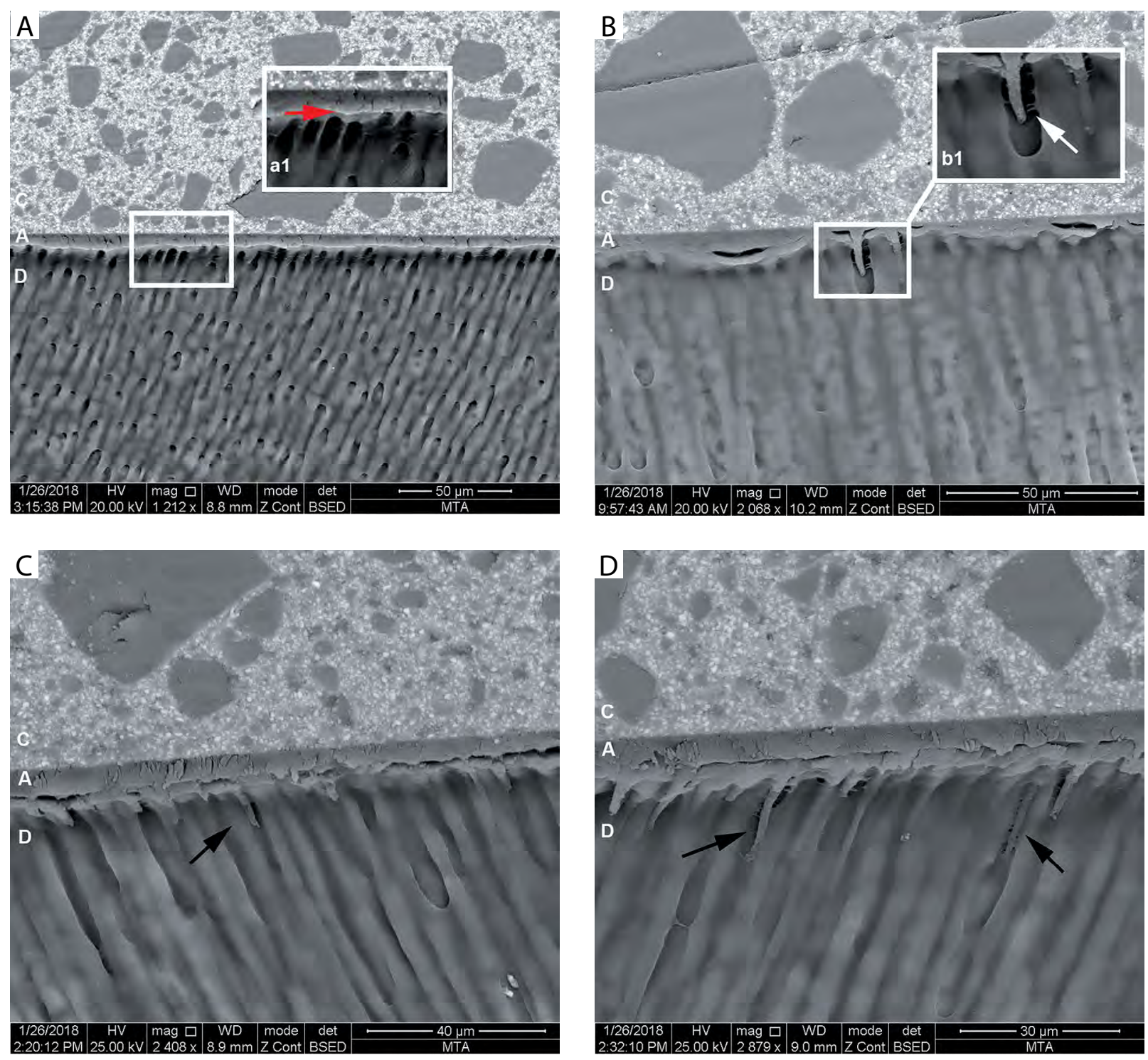

FIGURE 4. Representative scanning electron microscopy (SEM) images of the resin-dentin interface bonded with All Bond Universal adhesive in different etching modes. A) In self-etch mode, continuous hybrid layer (a1 - red arrow) with no resin tags. B-D) In etch-and-rinse mode with 5-s, 10-s, and 15-s etching. Cylindrical-shaped resin tags (black arrow) with lateral ramifications (b1 - white arrow). C - composite, A - adhesive, D - dentin

systems. Such adhesives can also self-assemble into nano-layers [39] and exhibit high hydrophobicity, which can support the hybrid layer formed from hydrolysis [38].

Etching dentin with phosphoric acid is a controversial issue. Some studies $[17,27]$ have shown that a reduced etching period (7 s) provided significantly higher dentin bond strength than a conventional etching period (15 s) for etch-and-rinse adhesives. In contrast, Sanabe et al. [24] found no significant differences between 7-15-s acid etching after 24-h water storage but noted that bond strength values decreased significantly for 15-s acid etching after 6 and 12 months of water storage. Studies with self-etch adhesives $[33,34]$ have also shown that the etching of dentine substrate could decrease bond strength for self-etch systems. Phosphoric acid can decalcify dentine to a higher degree than a self-etch adhesive is planned to penetrate. Incomplete resin penetration to the demineralised dentin tissue by the adhesive resin was therefore considered the major factor responsible for the reduction in bond strength $[3,34]$. In the present study, etching over $5 \mathrm{~s}$ led to a significant reduction in bond strength for all the universal adhesives tested. These results are critical because clinicians mostly restore cavities, which contain both dentine and tissues, in daily clinical practice. In this state, it can be proposed that when using universal adhesives, acid etching should be applied solely to the enamel. This outcome is in parallel with the results of previous studies, which have investigated 

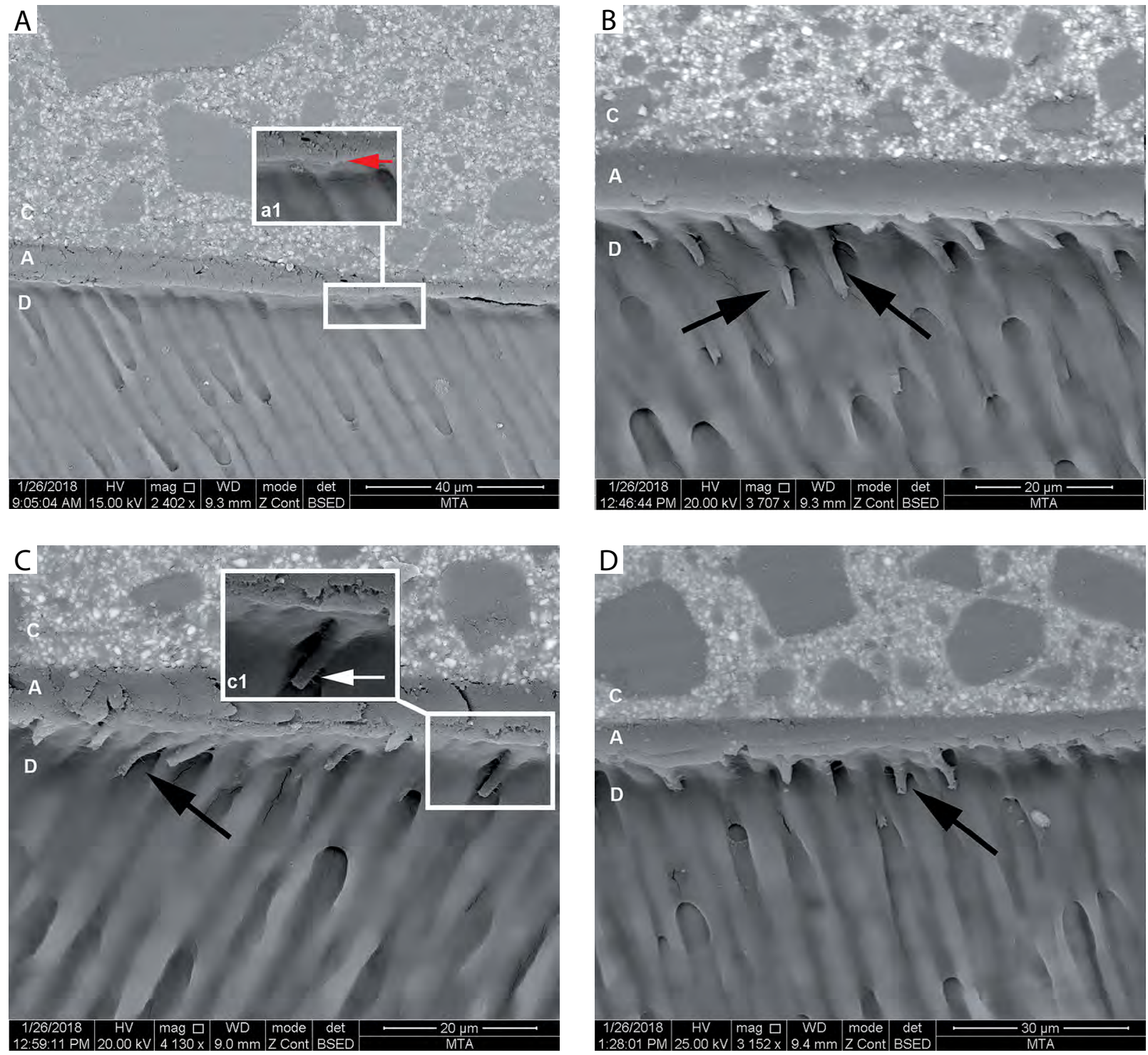

FIGURE 5. Representative scanning electron microscopy (SEM) images of the resin-dentin interface bonded with Clearfil Universal Bond in different etching modes. A) Self-etch mode, continuous and relatively thin hybrid layer (a1 - red arrow) and no resin tags. B-D) In etch-and-rinse mode with 5-s, 10-s, and 15-s etching. Upper portion of cylindrical-shaped resin tags (black arrow) with lateral ramifications (c1 - white arrow). C - composite, A - adhesive, D - dentin

bond strength on enamel and dentin after pre-etching of universal adhesives $[1,21]$.

Takamizawa et al. [28] investigated the effects of different acid-etching times on the shear bond and fatigue strength of self-etch adhesives to dentin. Researchers found that one of the tested adhesives showed a reduction in dentin bond strength with an extended etching period, and that the group with $15 \mathrm{~s}$ of etching exhibited significantly lower shear bond strength and shear fatigue strength values than the group without pre-etching. The other self-etch adhesives did not show a significant difference.

Wagner et al. [37] compared the micro-tensile bond strength of universal adhesives in etch-and-rinse and self-etch modes. In contrast to the results of our study, these authors found no significant difference in terms of the effects of etching modes. The major difference between these two studies was the artificial aging period. In the study by Wagner et al., the samples were subjected to artificial aging for 5000 cycles. In the current study, specimens were subjected to 10,000 cycles, and this extended period might have caused the observed reduction in bond strength values. Gale and Darvell [7] concluded that when considering long-term bonding efficacy, 10,000 cycles are equivalent to approximately 1 year of in vivo function. The artificial aging effect generated by thermo-cycling can develop in either of the two forms: high temperature may stimulate hydrolysis of components at the interface and cause extraction of breakdown products or poorly polymerised resin oligomers [9], or repetitive contraction/expansion stresses are generated 

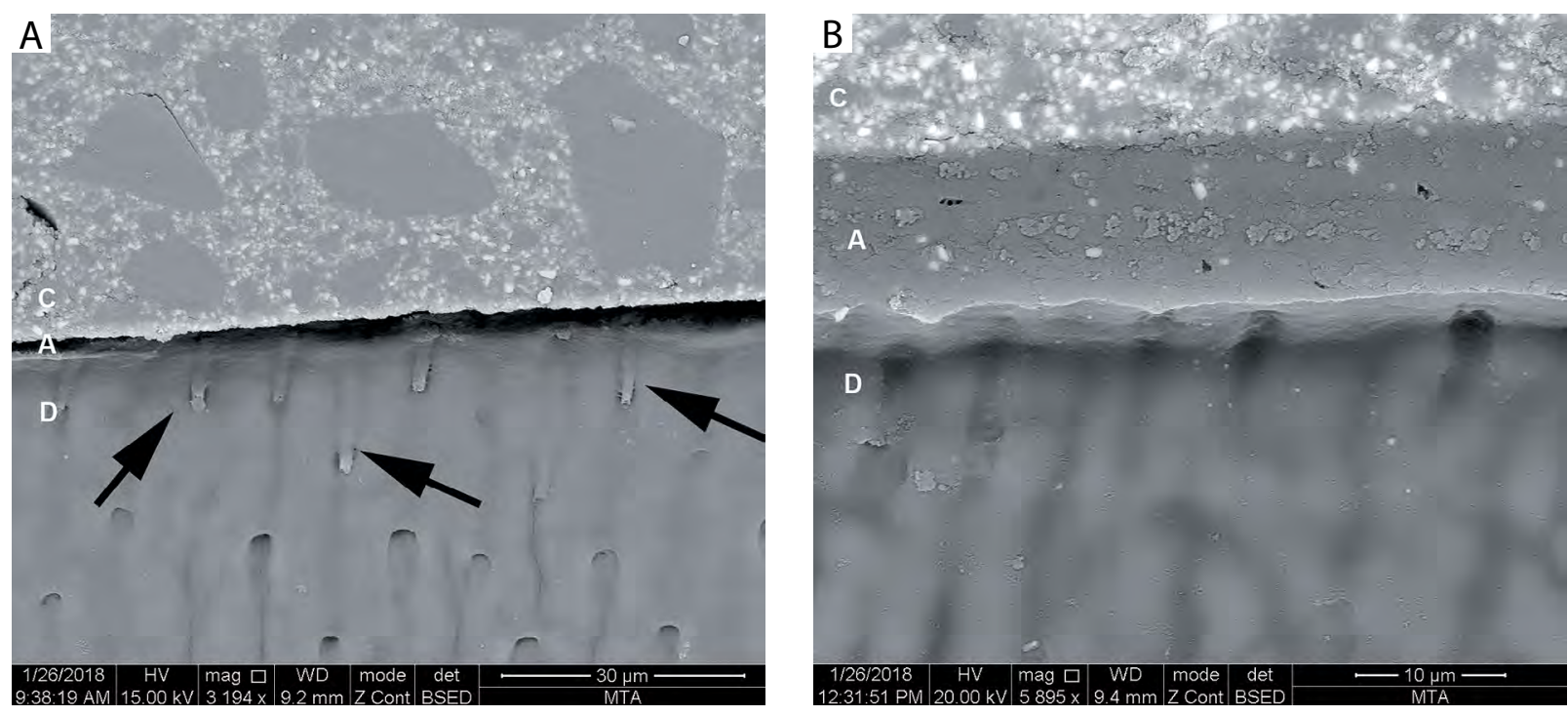

FIGURE 6. Representative scanning electron microscopy (SEM) images of the resin-dentin interface bonded with self-etch adhesives. A) Clearfil SE Bond. Upper portion of cylindrical-shaped resin tags (black arrow) without lateral ramifications. B) Clearfil S3 Bond Plus. Approximately $10 \mu \mathrm{m}$ thick adhesive layer with no resin tags. $\mathrm{C}-$ composite, $A$ - adhesive, $D$ - dentin

at the tooth-biomaterial interface because of different thermal contraction/expansion coefficients of the restorative material and the tooth tissue [7].

Hanabusa et al. [8] tested immediate (24-h water storage) $\mu \mathrm{TBS}$ to dentin using a self-etch adhesive with different protocols and found no significant differences between the effects of self-etch and etch-and-rinse mode. Although there was no reduction in bond strength, their ultra-structural analysis showed clear signs of low-quality hybridisation when the universal adhesives were deployed in etch-and-rinse mode. Therefore, these authors reported that zones in which resin had infiltrated poorly may have influenced the mechanical stability of adhesive bonding, and that the adhesive interface may have been more vulnerable to biodegradation. Furthermore, although phosphoric acid etching did not reduce the immediate bonding strength in dentin, some researchers have recommended that universal adhesives should be used only in the selfetch mode on the dentin $[8,23]$. The differences in results between the current study and previously published studies may be due to the fact that low-quality hybridisation areas in the adhesive interface may have been affected during the 10,000 cycles of artificial aging.

The SEM results obtained during the present study showed that the $\mathrm{pH}$ and etching mode affected the morphology of the resin-dentin interface. After the etching procedure ( $\mathrm{pH} \sim 0.1$ ), a thick, funnel-shaped hybrid layer was produced. On the other hand, for self-etch mode, a thin, continuous hybrid layer was produced without resin tags except $\mathrm{CSE}$ ( $\mathrm{pH}$ of $\mathrm{SBU}=2.7, \mathrm{ABU}>3$, $\mathrm{CUB}=2.3, \mathrm{CSE}=2, \mathrm{CS} 3=2.3$ ) [6]. This finding correlates with many previous investigations, which have indicated that the thickness of the hybrid layer depends on the applied acidity, but the bond strength depends on the quality and not on the thickness [13].

For long-term success of composite resin restorations, strong and stable bonding is required. Longterm clinical trials are considered the gold standard for evaluating the bonding quality [14]. However, conducting long-term clinical studies is difficult because there are variables such as operator differences, substrate differences, and follow-up and ethical issues [26]. Therefore, in vitro studies may be more effective in providing useful information for the potential clinical success of dentin adhesives.

Even though several studies have reported excellent bonding performance of dental adhesives over the immediate- and short-term $[2,10]$, some researchers have suggested that results in the long- and short-term studies are not correlated because of the rapid degradation of the hybrid layer [3-5]. Thus, in the current study, all samples were subjected to thermal cycling for aging to evaluate the long-term bonding performance of multimode universal adhesives.

In order to estimate the clinical performance of adhesive materials, laboratory bond strength assessments are commonly performed. In order to prevent premature failure caused by microcracks and structural defects, the $\mu$ SBS test, which did not require a trimming operation, was used in this study $[15,35]$. Another advantage of $\mu \mathrm{SBS}$ is its homogenous stress distribution. As a result, more adhesive-type failure and more reliable data can be obtained than in macro tests [31]. Failure analysis showed that most of the failures were partially or completely in the adhesive interface, which increased the validity of the results. 

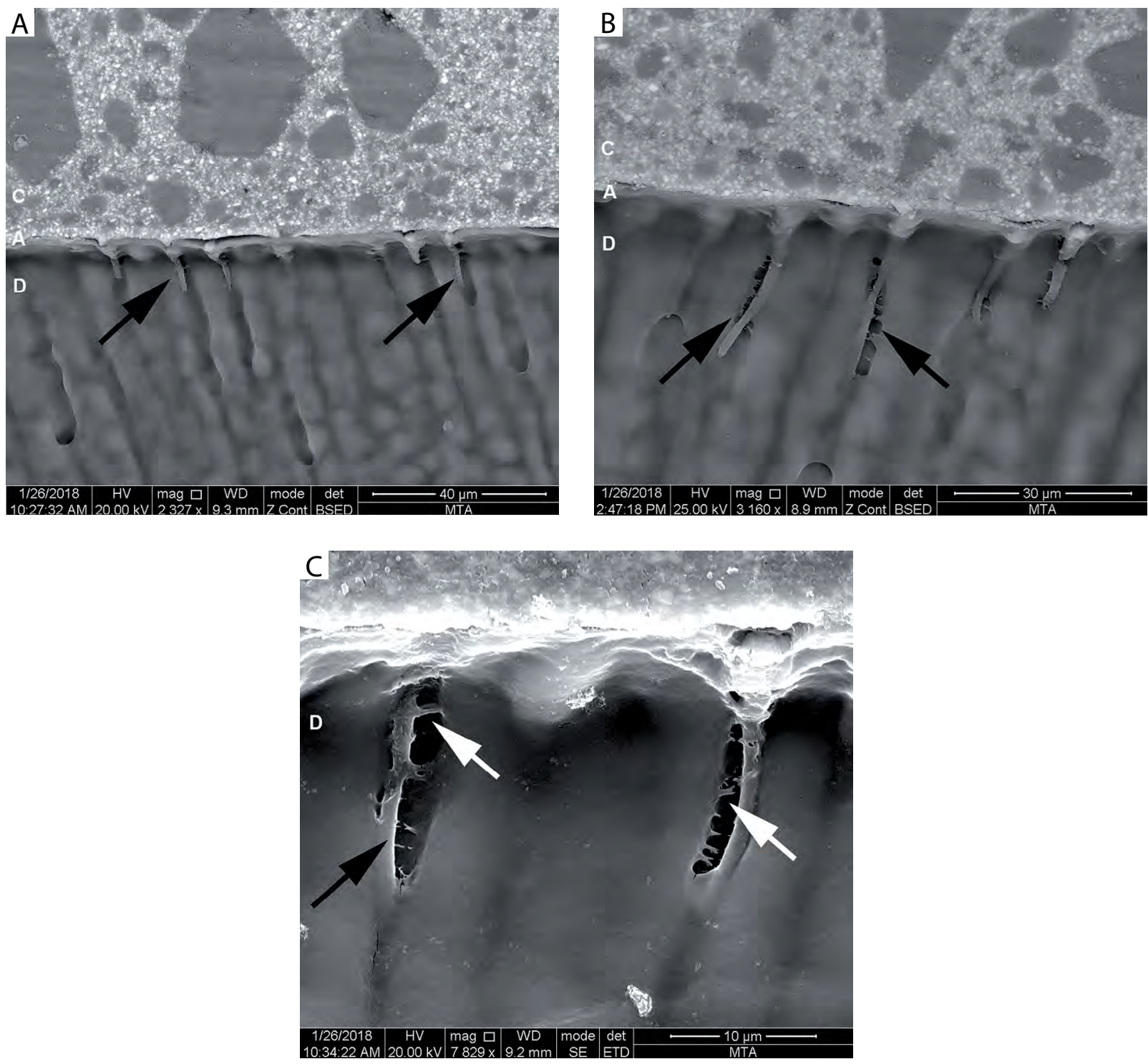

FIGURE 7. Representative scanning electron microscopy (SEM) images of the resin-dentin interface bonded with Adper Single Bond-2 in different etching periods. A-C) With 5-s, 10-s, and 15-s etching, respectively. Funnel-shaped resin tags (black arrow) with lateral ramifications (white arrow). C - composite, A - adhesive, D - dentin

\section{CONCLUSIONS}

Within the limitations of the present study, the use of an etchant before adhesive application significantly improved the pattern of dentine penetration; however, phosphoric acid treatment for $>5 \mathrm{~s}$ caused a significant reduction in $\mu \mathrm{SBS}$ results. In clinical conditions, it is very difficult to manage time for the acid-etching process. It is also difficult to apply the etchant to a specific tissue area. This study showed that even a 5-s extension of the etching time can change the $\mu$ SBS. In the etch-and-rinse mode, clinicians should consider that the etching time period does not extend when using universal adhesives. For selective-etch mode, clinicians should also consider that the etchant does not overflow the dentin surfaces.

\section{CONFLICT OF INTEREST}

The authors declare no potential conflicts of interest with respect to the research, authorship, and/or publication of this article.

\section{References}

1. Beltrami R, Chiesa M, Scribante A, Allegretti J, Poggio C. Comparison of shear bond strength of universal adhesives on etched and nonetched enamel. J Appl Biomater Funct Mater 2016; 14: e78-83.

2. Bradna P, Vrbova R, Dudek M, Roubickova A, Housova D. Comparison of bonding performance of self-etching and etch-andrinse adhesives on human dentin using reliability analysis. J Adhes Dent 2008; 10: 423-429.

3. Breschi L, Mazzoni A, Ruggeri A, Cadenaro M, Di Lenarda R, De Stefano Dorigo E. Dental adhesion review: aging and stability of the bonded interface. Dent Mater 2008; 24: 90-101. 
4. Cetin AR, Unlu N, Cebe MA. Effects of aging on the bond strength of self-etching adhesives and resin luting cements. J Dent Sci 2013; 8: 61-67.

5. De Munck J, Van Landuyt K, Peumans M, et al. A critical review of the durability of adhesion to tooth tissue: methods and results. J Dent Res 2005; 84: 118-132.

6. Ermis RB, De Munck J, Cardoso MV, et al. Bond strength of selfetch adhesives to dentin prepared with three different diamond burs. Dent Mater 2008; 24: 978-985.

7. Gale MS, Darvell BW. Thermal cycling procedures for laboratory testing of dental restorations. J Dent 1999; 27: 89-99.

8. Hanabusa M, Mine A, Kuboki T, et al. Bonding effectiveness of a new 'multi-mode' adhesive to enamel and dentine. J Dent 2012 40: 475-484

9. Hashimoto M, Ohno H, Kaga M, Endo K, Sano H, Oguchi H. In vivo degradation of resin-dentin bonds in humans over 1 to 3 years. J Dent Res 2000; 79: 1385-1391.

10. Inoue S, Vargas MA, Abe Y, et al. Microtensile bond strength of eleven contemporary adhesives to dentin. J Adhes Dent 2001; 3: 237-245.

11. Kanca J 3rd. Resin bonding to wet substrate. 1. Bonding to dentin. Quintessence Int 1992; 23: 39-41.

12. Kanca J 3rd. Wet bonding: effect of drying time and distance. Am J Dent 1996; 9: 273-276.

13. Kenshima S, Francci C, Reis A, Loguercio AD, Filho LER. Conditioning effect on dentin, resin tags and hybrid layer of different acidity self-etch adhesives applied to thick and thin smear layer J Dent 2006; 34: 775-783.

14. Koumpia E, Dionysopoulos P, Koumpia E. In vivo evaluation of microleakage from composites with new dentine adhesives. J Oral Rehabil 2004; 31: 1014-1022.

15. McDonough WG, Antonucci JM, He J, et al. A microshear test to measure bond strengths of dentin-polymer interfaces. Biomaterials 2002; 23: 3603-3608.

16. Miller MB. Self-etching adhesives: solving the sensitivity conundrum. Pract Proced Aesthet Dent 2002; 14: 406.

17. Osorio R, Aguilera FS, Otero PR, et al. Primary dentin etching time, bond strength and ultra-structure characterization of dentin surfaces. J Dent 2010; 38: 222-231.

18. Pashley DH, Tay FR, Breschi L, et al. State of the art etch-andrinse adhesives. Dent Mater 2011; 27: 1-16.

19. DH, Tay FR, Carvalho RM, et al. From dry bonding to water-wet bonding to ethanol-wet bonding. A review of the interactions between dentin matrix and solvated resins using a macromodel of the hybrid layer. Am J Dent 2007; 20: 7-20.

20. Peumans M, De Munck J, Van Landuyt KL, Poitevin A, Lambrechts P, Van Meerbeek B. Eight-year clinical evaluation of a 2-step self-etch adhesive with and without selective enamel etching. Dent Mater 2010; 26: 1176-1184.

21. Poggio C, Beltrami R, Colombo M, Chiesa M, Scribante A. Influence of dentin pretreatment on bond strength of universal adhesives. Acta Biomater Odontol Scand 2017; 3: 30-35.

22. Reis A, Loguercio AD, Azevedo CL, de Carvalho RM, da Julio Singer M, Grande RH. Moisture spectrum of demineralized dentin for adhesive systems with different solvent bases. J Adhes Dent 2003; 5: 183-192.

23. Rosa WL, Piva E, Silva AF. Bond strength of universal adhesives: a systematic review and meta-analysis. J Dent 2015; 43: 765-776.

24. Sanabe ME, Kantovitz KR, Costa CA, Hebling J. Effect of acid etching time on the degradation of resin-dentin bonds in primary teeth. Am J Dent 2009; 22: 37-42.

25. Sano H, Kanemura N, Burrow MF, Inai N, Yamada T, Tagami J. Effect of operator variability on dentin adhesion: students vs. dentists. Dent Mater J 1998; 17: 51-58.

26. Sano H, Yoshikawa T, Pereira PN, et al. Long-term durability of dentin bonds made with a self-etching primer, in vivo. J Dent Res 1999; 78: 906-911.

27. Sardella TN, de Castro FL, Sanabe ME, Hebling J. Shortening of primary dentin etching time and its implication on bond strength. J Dent 2005; 33: 355-362.
28. Takamizawa T, Barkmeier WW, Tsujimoto A, et al. Influence of different pre-etching times on fatigue strength of self-etch adhesives to dentin. Eur J Oral Sci 2016; 124: 210-218.

29. Tay FR, Gwinnett JA, Wei SH. Micromorphological spectrum from overdrying to overwetting acid-conditioned dentin in water-free acetone-based, single-bottle primer/adhesives. Dent Mater 1996; 12: 236-244.

30. Tay FR, King NM, Chan KM, Pashley DH. How can nanoleakage occur in self-etching adhesive systems that demineralize and infiltrate simultaneously? J Adhes Dent 2002; 4: 255-269.

31. Thanaratikul B, Santiwong B, Harnirattisai C. Self-etch or etchand-rinse mode did not affect the microshear bond strength of a universal adhesive to primary dentin. Dent Mater J 2016; 35: 174-179.

32. van Dijken JW, Sunnegardh-Gronberg K, Lindberg A. Clinical long-term retention of etch-and-rinse and self-etch adhesive systems in non-carious cervical lesions. A 13 years evaluation. Dent Mater 2007; 23: 1101-1107.

33. Van Landuyt KL, Kanumilli P, De Munck J, Peumans M, Lambrechts P, Van Meerbeek B. Bond strength of a mild self-etch adhesive with and without prior acid-etching. J Dent 2006; 34: 77-85.

34. Van Landuyt KL, Peumans M, De Munck J, Lambrechts P, Van Meerbeek B. Extension of a one-step self-etch adhesive into a multi-step adhesive. Dent Mater 2006; 22: 533-544.

35. Van Landuyt KL, Yoshida Y, Hirata I, et al. Influence of the chemical structure of functional monomers on their adhesive performance. J Dent Res 2008; 87: 757-761.

36. Van Meerbeek B, Yoshihara K, Yoshida Y, Mine A, De Munck J, Van Landuyt KL. State of the art of self-etch adhesives. Dent Mater 2011; 27: 17-28

37. Wagner A, Wendler M, Petschelt A, Belli R, Lohbauer U. Bonding performance of universal adhesives in different etching modes. J Dent 2014; 42: 800-807.

38. Yoshida Y, Yoshihara K, Nagaoka N, et al. Self-assembled nanolayering at the adhesive interface. J Dent Res 2012; 91: 376-381.

39. Yoshihara K, Yoshida Y, Nagaoka N, et al. Nano-controlled molecular interaction at adhesive interfaces for hard tissue reconstruction. Acta Biomater 2010; 6: 3573-3582. 